\title{
PEMBERIAN PENDIDIKAN KESEHATAN TENTANG PENANGANAN KEJANG DEMAM PADA ANAK BALITA TERHADAP TINGKAT KECEMASAN PADA IBU
}

\author{
Andriani Angelia Alda Pelealu \\ Ora Et Labora Palendeng \\ Vandri Kallo \\ Program Studi Ilmu Keperawatan Fakultas Kedokteran \\ Universitas Sam Ratulangi \\ Email : andrianipelealu20@gmail.com
}

\begin{abstract}
Absrtack : Febrile seizures are seizures that occur at an increase in body temperature (temperature $38^{\circ}$ C) caused by an extracranial process. This is as a factor in increasing anxiety levels for mothers. The Distribution of health education is very important to control the anxiety levels, because of anxiety levels in mother can affected into the point view and behavior that she would do next. The aim of this study was to determine the effect of providing health education on the management of febrile seizures in children to the level of anxiety in mothers at the RSU GMIM Pancaran Kasih Manado. The research method used the quasy experiment method with the pretest-posttest one group design. Respondents consisted of 15 respondents with the technique of determining the sample using a different test formula 2 proportions. Data collection using a questionnaire. Wilcoxon Signed Rank. Test Results where the value of $p$ value $=0.001$ is smaller than $\alpha=0.05$. Conclusion Health education is very decisive at the level of consideration in the mother. In this study, the respondent's response to the level of participation before being carried out and after taking action to provide health education about the management of febrile seizures in children under five was obtained by the respondent's level or the mother became mildly anxious.
\end{abstract}

Keywords: Health Education, Fever Seizures, Anxiety Level.

\begin{abstract}
Abstrak : Kejang demam merupakan bangkitan kejang yang terjadi pada kenaikan suhu tubuh (suhu $38^{\circ} \mathrm{C}$ ) yang disebabkan oleh suatu proses ekstrakranium. Hal ini disadari sebagai salah satu faktor tingkat kecemasan pada sebagian besar ibu bertambah. Pemberian pendidikan kesehatan sangat penting agar tingkat kecemasan dapat berubah, karena perubahan tingkat kecemasan pada ibu juga mempengaruhi cara pandang dan tindakan yang akan dilakukan selanjutnya. Tujuan peneliti ini adalah untuk mengetahui pengaruh pemberian pendidikan kesehatan tetang penanganan kejang demam pada anak terhadap tingkat kecemasan pada ibu di RSU GMIM Pancaran Kasih Manado. Metode penelitian menggunakan metode quasy experiment dengan pretest-posttest one group design. Responden terdiri dari 15 responden dengan teknik penentuan sampel menggunakan rumus uji beda 2 proporsi . Pengumpulan data menggunakan kuesioner. Hasil Uji Wilcoxon Signed Rank Test dimana nilai $\mathrm{p}$ value $=0,001$ lebih kecil dari $\alpha=0,05$. Kesimpulan terdapat pengaruh pemberian pendidikan kesehatan tentang penanganan kejang demam pada anak balita terhadap tingkat kecemasan pada ibu . Kesimpulan pendidikan kesehatan sangat berpengaruh pada tingkat kecemasan pada ibu. Dalam penelitian ini mayoritas responden memiliki tingkat kecemasan sedang sebelum dilakukan dan setelah dilakukan tindakan pemberian pendidikan kesehatan tentang penanganan kejang demam pada anak balita didapatkan tingkat kecemasan responden atau ibu menurun menjadi cemas ringan.
\end{abstract}

Kata Kunci : Pendidikan Kesehatan, Kejang demam, Tingkat Kecemasan 


\section{PENDAHULUAN}

Demam merupakan peningkatan suhu tubuh diatas rentang normal yang tidak teratur dan disebabkan ketidakseimbangan antara produksi dan pembatas panas (Sodikin, 2012). Kejang demam merupakan gangguan transier pada anak-anak yang terjadi bersamaan dengan demam. Jika tidak ditangani dengan baik maka beresiko kematian kematian (Lumbantobing, 2003). Kejang demam sangat berhubungan dengan usia, hampir tidak pernah ditemukan sebelum usia 6 bulan dan setelah 6 tahun (Hull, 2008). Angka kejadian kejang demam di Amerika Serikat dan di Eropa Barat pada tahun 2007 berkisar antara 8\%-49\% (Brough, 2008). Angka kejadian di Asia pada tahun 2007 dari seluruh kejang ditemukan 20\% anak mengalami kejang demam kompleks (Wardani, 2013).

WHO (World Heald Organization) memperkirakan pada tahun 2005 terdapat lebih dari 21,65 juta penderita kejang demam dan lebih dari 216 ribu diantaranya meninggal. Insiden dan prevalensi kejang demam di Eropa pada tahun 2006 berkisar 2-5\%, di Asia prevalensi kejang demam lebih besar sebesar 8,3-9,9\% pada tahun yang sama. Angka kejadian kejang demam di Indonesia sendiri mencapai $2-4 \%$ tahun 2008 dengan $80 \%$ disebabkan oleh infeksi saluran pernafasan. Angka kejadian di wilayah Jawa Tengah sekitar2-5\% pada anak usia 6 bulan-5 tahun disetiap tahunnya. 25-50\% kejang demam akan mengalami bangkitan kejang demam berulang (Gunawan, 2008).

Kejadian kejang demam dapat menyebabkan perasaan ketakutan berlebihan, trauma secara emosi dan kecemasan pada orang tua (Jones \& Jacobsen, 2007).Pengalaman pertama orang tua saat melihat anak kejang demam, menimbulkan ketakutan pada orang tua, orang tua takut anak kejang setiap demam. Hal ini menjadi masalah dan sangat mengganggu (Najimi, 2013) .

Dalam (Hawari,2011) Ansietas merupakan pengalaman individu yang bersifat subjektif, yang sering bermanifestasi sebagai perilaku yang disfungsional yang diartikan sebagai perasaan "kesulitan" dan kesusahan terhadap kejadian yang tidak diketahui dengan pasti (Varcarolis, 2007). Pendapat lain juga menyatakan Kecemasan merupakan reaktivitas emosional berlebihan, depresi yang tumpul, atau konteks sensitif, respon emosional (Clift, 2011)

Tingkat pengetahuan orang tua yang berbeda dapat mempengaruhi pencegahan kejang demam pada anak saat anak mengalami demam tinggi (Riandika, 2012). Kecemasan berlebihan disebabkan karena edukasi yang tidak memadai tentang kejang demam (Tarigan, Harahap $\&$ Lubis, 2007). Sehingga dari uraian di atas peneliti tertarik untuk meneliti "Pengaruh pemberian pendidikan kesehatan tentang penanganan kejang demam terhadap tingkat kecemasan pada ibu di RSU GMIM Pancaran Kasih Manado".

\section{METODE PENELITIAN}

Jenis penelitian yang digunakan merupakan penelitian dengan pendekatan kuantitatif dengan desain penelitian quasy experiment dengan pretest-posttest one group design yaitu membandingkan tentang (tingkat kecemasan pada ibu sebelum dan sesudah pemberian pendidikan kesehatan.) Penelitian ini dilakukan di RSU GMIM Pancaran Kasih Manado pada tanggal 05-20 Juni 2019. Populasi pada penelitian ini yaitu ibu dengan anak kejang demam yang sedang dirawat di RSU GMIM Pancaran Kasih Manado selama 2 bulan terakhir yaitu sebanyak 45 ibu. Pengambilan sampel pada penelitian ini dilakukan secara non probability sampling dengan teknik purposive sampling dengan menggunakan rumus uji beda 2 proporsi, dan didapatkan sebenyak 15 responden. Instrument penelitian yang digunakan dalam penelitian ini yaitu dengan kuisioner kecemasan STAI yang sudah dipakai 
sebelumnya oleh (Bantelu,2015), kuisioner ini terdri dari 20 pernyataan dengan point soal yang menilai adanya tingkat kecemasan kriteria jawaban skor 1 :Tidak sama sekali, 2: Sedikit, 3: sedang, 4: Sangat dan juga pernyataan dengan menilai ketidakberadaan kecemasan dengan point 4: tidak sama sekali, 3: sedikit, 2: sedang, 1 : sangat. Setelah dilakukan penelitian, kuisioner yang telah di kumpul kemudian di beri skor untuk menentukan tingkat kecemasan sebelum dan sesudah diberikan pendidkan kesehatan, dan dilakukan analistik uji statistic melalui system computer dengan beberapa tahap yaitu editing, coding, cleaning, tabulating. Analisa bivarian dalam penelitian ini dilakukan perhitungan untuk mengetahui pengaruh pemberian pendidikan kesehatan tentang penangan kejang demam pada anak balita dengan tingkat kecemasan pada ibu di RSU GMIM Pancaran Kasih Manado. Peneliti menggunakan aplikasi computer dan dianalisis dengan uji wilcoxon signed rank test dengan nilai kemaknaan $95 \%(\alpha=0,05)$

\section{HASIL dan PEMBAHASAN}

\section{Karakteristik Responden}

Tabel 1. Karakteristik responden berdasarkan umur

\begin{tabular}{ccc}
\hline Umur & $\mathbf{n}$ & $\boldsymbol{\%}$ \\
\hline $20-25$ & 5 & 33,03 \\
$26-30$ & 6 & 40 \\
$>30$ & 4 & 26,07 \\
\hline Total & $\mathbf{1 5}$ & $\mathbf{1 0 0}$ \\
\hline
\end{tabular}

Sumber: data primer, 2019

Hasil penelitian berdasarkan tabel di atas menunjukan bahwa sebagian besar berada pada pada rentang umur 26-30 sebanyak 6 (40\%). Sejalan dengan penelitian oleh (Suhartik,2014), bahwa usia sebagian besan responden yang berdada pada kategori massa dewasa awal, cukup matang dalam cara berpikir dan menanggapi informasi yang didapat.

Tabel 2.Distribusi responden berdasarkan pendidikan terakhir

\begin{tabular}{ccc}
\hline $\begin{array}{c}\text { Pendidikan } \\
\text { Terakhir }\end{array}$ & n & \% \\
\hline SMA & 5 & 33,03 \\
D4 & 1 & 6,7 \\
S1 & 9 & 60 \\
\hline Total & $\mathbf{1 5}$ & $\mathbf{1 0 0}$ \\
\hline
\end{tabular}

Sumber: data primer, 2019

Penelitian ini menunjukkan bahwa sebagian besar sampel memilki pendidikan terakhir yaitu S1 sebanyak 9 responden (60\%). Sejalan dengan penelitian yang dilakukan oleh (Suhartik,2014) bahwa mayoritas yang berpendidikan tinggi dapat mengambil keputusan secara matang dalam menerima suatu hal dan dimana berpendidikan tinggi mempengaruhi persepsi seseorang untuk mengambil keputusan dan bertindak. (Notoatmodjo,2007 ).

Tabel 3. Distribusi responden berdasarkan status pekerjaan

\begin{tabular}{ccc}
\hline Pekerjaan & n & \% \\
\hline Guru & 1 & 6,07 \\
IRT & 8 & 53,03 \\
K.Swasta & 4 & 26,07 \\
Pendeta & 1 & 6,07 \\
Wiraswasta & 1 & 6,07 \\
\hline Total & $\mathbf{1 5}$ & $\mathbf{1 0 0}$ \\
\hline
\end{tabular}

Sumber: data primer, 2019

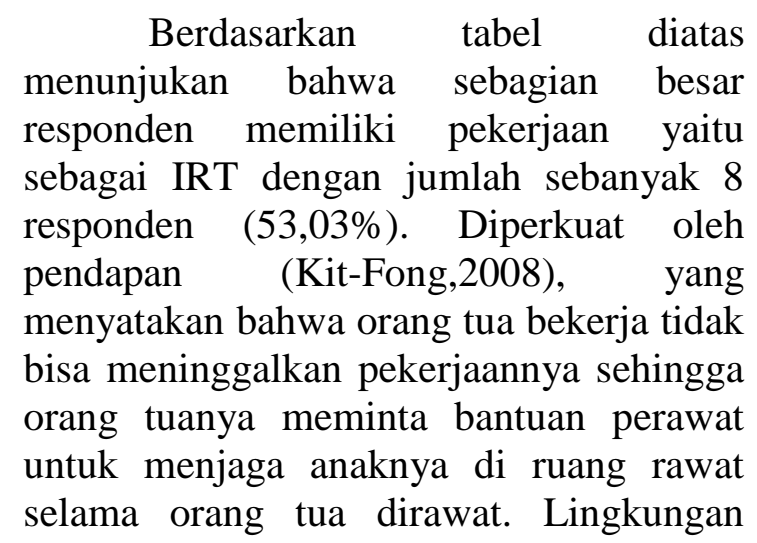


pekerjaan dapat menjadikan seseorang memperoleh pengalaman dan pengetahuan baik secara langsung maupun secara tidak langsung. Contohnya, seseorang yang bekerja sebagai tenaga medis akan lebih mengerti dan juga tidak cemas dalam mengenai demam dan pengalolaannya daripada non tenagamedis (Notoatmodjo, 2003).

\section{Analisa Univariat}

Tabel 3. Tingkat Kecemasan Pre Pendidikan Kesehatan

\begin{tabular}{lcc}
\hline Kategori & n & \% \\
\hline Rendah & 1 & 6,07 \\
Sedang & 5 & 33,03 \\
Tinggi & 9 & 60 \\
Total & $\mathbf{1 5}$ & $\mathbf{1 0 0 \%}$ \\
\hline
\end{tabular}

Sumber: data primer, 2019

Penelitian ini tabel diatas menunjukkan bahwa sebagian besar sampel mendapatan tingkat kecemasan cemas sedang yaitu sebesar 6 responden (40\%). Menurut (Ervina,2013) bahwa salah satu faktor yang mempengaruhi tingkat kecemasan yaitu fasilitas sebagai sumber inormasi yang dapat mempengaruhi seseorang. Sejalan dengan penelitian oleh (Suhartik,2014) bahwa sebagian besar ibu yang tidak banyak mempunyai informasi mengenai penangan kejang demam pada anak memiliki self efficacy rendah, sehinggah cenderung ibu tidak dapat memutuskan keputusan secara baik yaitu menujukan sebanyak 11,05\% responden yang memiliki self efficacy rendah.

Tabel 4. Tingkat Kecemasan Post Pendidikan Kesehatan

\begin{tabular}{ccc}
\hline Kategori & n & \% \\
\hline Rendah & 2 & 13,03 \\
Sedang & 9 & 60 \\
Tinggi & 4 & 26,07 \\
\hline Total & $\mathbf{1 5}$ & $\mathbf{1 0 0 \%}$ \\
\hline
\end{tabular}

Sumber: data primer, 2019

Tabel diatas menunjukan bahwa sebagian besar sampel mendapatkan tingkat kecemasan dikategorikan cemas ringan dengan responden sebanyak 6 responden $(40 \%)$. Hal ini didukung oleh penelitian yang dilakukan oleh (Ervina,2013) bahwa ibu dengan pengetahuan yang tinggi bias memiliki kemampuan atau mengantisipasi pencegahan terhadap kejang demam pada anak.

\section{Analisa Bivariat}

Tabel 5. Pengaruh pemberian pendidikan kesehatan tentang penanganan kejang demam pada anak balita terhadap tingkat kecemasan klien

\begin{tabular}{|c|c|c|c|c|c|}
\hline & $n$ & Mean & Minimum & Maximum & $\rho$ value \\
\hline $\begin{array}{l}\text { Pre } \\
\text { Test }\end{array}$ & 15 & 51,53 & 20 & 70 & 0,001 \\
\hline $\begin{array}{l}\text { Post } \\
\text { Test }\end{array}$ & 15 & 35,60 & 20 & 65 & \\
\hline
\end{tabular}

Sumber: data primer, 2019

Berdasarkan hasil pengelolahan data yang menggunakan perhitungan Wilcoxon Signed Rank Test dengan bantuan program komputer didapatkan hasil nilai $\mathrm{P}$ value 0,001 lebih kecil dari nilai $\mathrm{p} \quad(p<0,005)$. Maka dapat disimpulkan adanya pengaruh antara pemberian pendidikan kesehatan tentang penanganan kejang demam pada anak balita dengan tingkat kecemasan pada ibu di RSU GMIM Pancaran Kasih Manado. Pemberian pendidikan kesehatan sangat berpengaruh pada tingkat kecemasan seseorang. Pada saat anak mengalami kejang demam ibu dapat mengatasi dengan didasari oleh pengetahuan yang telah didapat. Hal ini sesuai dengan pendapat (Setyarini, 2009) bahwa frekuensi penyuluhan mempengaruhi pengambilan keputusan seseorang.

\section{SIMPULAN}

Pemberian pendidikan kesehatan sangat berpengaruh pada tingkat kecemasan pada ibu dalam menghadapi suatu keadaan dalam hal ini yaitu pada saat anak mengalami kejang demam. Dalam penelitian ini mayoritas responden memiliki tingkat kecemasan sedang 
sebelum dilakukan tindakan pemberian pendidikan kesehatan, dan setelah dilakukan tindakan pemberian pendidikan kesehatan tentang penanganan kejang demam pada anak balita didapatkan tingkat kecemasan responden atau ibu menurun menjadi cemas ringan.

\section{DAFTAR PUSTAKA}

Bantelu, F.E.M, (2015). Perbedaan tingkat kecemasan dalam proses menyusui antara ibu primipara dan multipara di RS Pancaran Kasih Manado.

Brough. H. (2008). Rujukan cepat pediatric \& kesehatan anak. EGC. Jakarta

Ervina.T.U (2013), Hubungan Antara Tingkat Pengetahuan Ibu Tentang Kejang Demam Dengan Frekuensi Kejang Anak Toddler Di Rawat Inap Puskesmas Gatak Sukoharjo,skripsi (tidak diterbitkan). Fakultas Ilmu Kesehatan : Universitas Muhammadiyah Surakarta

Hull, D \& Joohnston DI.( 2008). Dasar dasar pediatrik. Edisi 3, EGC. Jakarta.

Hawari, R. P. (2011). Management Stress, Cemas dan Depresi. Jakarta : FK UI.

Jones, T., \& Jacobsen, S.J. (2007). Childhood Febrile Seizures: Overview and Implications. International Journal of Medical Sciences.. ISSN 1449-1907 www.medsci.org.

Lumbantobing, S.M. (2003). Penatalaksanaan Muthakhir Kejang Pada Anak. Jakarta: FKUI

Najimi, A., Dolatabadi, N.A., Esmaeili, A.A., Sharifirad, G.R. (2013). The effect of educational program on knowledge, attitude and practice of mothers regarding] prevention of febrile seizure in children. J Edu Health Promot.
Notoatmodjo.(2007). Pendidikan dan Prilaku Kesehatan.PT. Rineka Cipta: Jakarta

Randika (2012) Hubungan antara tingkat pengetahuan ibu tentang demam dengan pengelolaan demam pada anak,Skripsi. Universitas Diponegoro, Semarang.

Tarigan, T., Harahap, C.A., \& Lubis, S. (2007). Pengetahuan, sikap dan perilakuorangtua tentang demam dan pentingnya edukasi oleh dokter. Sari Pediatri.

Sodikin (2012), prinsip perawatan demam pada anak, pustaka pelajar, Yogyakarta

Suhartik (2014) Pengaruh Pendidikan Kesehatan Penangan Kejang Demam Pada Balita dengan Tingkat Self Efficacy, Surakarta

Setriyani D..(2009). Pengaruh Intensitas Penyuluhan terhadap tingkat partisipasi masyarakat dalam program penghijauan kota: Universitas Indonesia. Skripsi

Wardani, AK, (2013). Kejang demam sederhana pada anak usia satu tahun. Medula,Vol.1,No.1,Hal5764:

http://portalgaruda.org/download_ article.php?article $=122474$. diakses 20 April 2019.

WHO. (2005). A Riview of Literature on Healthy Environment for the Children in the Eastern Mediterranean Region : Status of Children Lead Exposure. http://www.emro.who.int/dsaf/dsa5 16.pdf. Akses 12 September 2018. 